\title{
Commentary
}

\section{Doing no harm: A commentary on 'The clinical significance of co-morbid post- traumatic stress disorder and borderline personality disorder: Case study and literature review'}

NICHOLAS D. GIARDINO, Department of Psychiatry, University of Michigan, USA

The high co-morbidity of post-traumatic stress disorder (PTSD) and borderline personality disorder (BPD) is likely to be well known to clinicians who frequently treat patients with personality disorders and trauma-related mental health problems. But while evidence-based treatments are available for both PTSD and BPD, the co-occurrence of both disorders may raise a red flag for treatment providers, or at least a yellow light urging us to proceed with caution. Trainees in psychotherapy often assume that the presence of both diagnoses is a contraindication for the use of treatments such as prolonged exposure for PTSD. And even experienced clinicians may be wary of the co-morbidity and reflexively adjust their expectations for treatment success of one condition or the other. In their case study and literature review of this important topic, Links and Vignarajah show that, to the question of how to treat individuals in this population, we may have little to fear but fear itself.

This is not to say that clinical concerns about co-morbid patients are baseless. The authors describe the consistent finding that patients who present with both PTSD and BPD are likely to exhibit greater symptoms of anxiety, anger, avoidance, impulsivity and suicidality than those with either one diagnosis. But the results of several studies reviewed indicate that the presence of both disorders does not seem to affect the clinical presentation of the other disorder per se. Of both scientific and clinical interest is the question of why PTSD and BPD co-occur so frequently. In their review, a number of possibilities were addressed, including common early sexual abuse experiences and the impact of one disorder on risk for later developing the other. However, in addition to the impact of trauma per se on the risk for developing PTSD, the experience of sexual abuse in early life could also indicate the presence of an invalidating environment, which, according to Linehan (1993), may impair the development of healthy emotion regulation abilities, imparting risk for both BPD and PTSD.

In addition to childhood abuse, poor psychological adjustment and poor social support are common risk factors for both BPD and PTSD (Brewin, Andrews, \& Valentine, 2000; Ozer, Best, Lipsey, \& Weiss, 2003). Individuals with BPD may also be at increased risk for re-exposure to trauma in adulthood (Zanarini, Frankenburg, Reich, Hennen, \& Silk, 2005). Also, the presence of BPD may increase the risk for developing PTSD following trauma exposure, possibly due to lack of adequate coping resources (Gunderson \& Sabo, 1993). 
Finally, PTSD may impact BPD risk and clinical course. In their review, Links and Vignarajah describe the longitudinal study of BPD and PTSD symptoms in Gulf War veterans (Axelrod, Morgan, \& Southwick, 2005), which showed that predeployment BPD symptoms were associated with PTSD symptoms at 6 months post deployment, and that self-reported trauma exposure and PTSD symptoms were associated with post-deployment BPD symptoms. Links and Vignarajah state that the described study's authors 'concluded that traumatic experiences and PTSD in adulthood can lead to BPD'. But this is not exactly correct. Axelrod et al. are careful to state that trauma and PTSD may contribute to the development of 'borderline personality features [italics added]' and, elsewhere in their discussion 'borderline personality disorder-like personality changes that cause clinically significant distress or impairment'. They explain that 'living with these symptoms may lead to a number of experiences commonly associated with borderline personality disorder, including marked affective instability, unstable and intense interpersonal relationships, and inappropriate intense anger'. There was no evidence of new onset BPD per se as a consequence of trauma exposure or PTSD in this study. However, the presence of trauma or PTSD may impact the natural course of BPD. In a longitudinal study of BPD, PTSD and adult abuse experiences are associated with a decreased likelihood of BPD remission at a 6-year follow-up assessment (Zanarini, Frankenburg, Hennen, Reich, \& Silk, 2004; Zanarini et al., 2005).

Common neurobiological differences may underlie some of the common features of PTSD and BPD, including poor emotion regulation and increased stress reactivity, which may contribute to the risk for co-morbidity. Both patient groups show hyperactivity in hypothalamic pituitary adrenal (HPA) axis functioning and hyperresponsiveness of the HPA axis to pharmacological stimulation (Bremner et al., 1997; Carrasco et al., 2007; Lange et al., 2005; Rinne et al., 2002; Yehuda et al., 1993). BPD and PTSD patients also show lower platelet alpha 2-adrenergic receptors (Perry, Giller, \& Southwick, 1987; Southwick, Yehuda, Giller, \& Perry, 1990). Brain imaging studies indicate that both disorders are associated with smaller hippocampus volume (Bremner et al., 1995; Driessen et al., 2000), greater activation of the amygdala (Herpertz et al., 2001; Liberzon et al., 1999) and less anterior cingulate (Bremner et al., 2004; Minzenberg, Fan, New, Tang, \& Siever, 2007; Shin et al., 2001) and medial prefrontal cortex activity (Bremner et al., 1999; Phan, Britton, Taylor, Fig, \& Liberzon, 2006; Silbersweig et al., 2007) in response to stressful emotional stimuli.

On the topic of treatment, Links and Vignarajah show that any hesitations we may have to apply evidenced-based treatments for BPD or PTSD to patients with both disorders will receive little support from the treatment research literature. Data from a number of studies that included patients with co-morbid BPD and PTSD find that, not only are the treatments effective for the target condition, but also effective treatment of one condition appears to provide some symptom relief in the other. This seems to be particularly true for PTSD treatments, where effective treatment of PTSD also produces improvement in BPD symptoms. Links and Vignarajah correctly report that, in treatment studies that have included and identified patients with both PTSD and BPD, the successful treatment of one disorder does not also lead to complete remission of the other in most patients. It should not be too surprising that empirically supported treatments for PTSD do not completely treat BPD and vice versa. First, the treatments were not designed to target both disorders. Second, the occurrence of such dual treatment effects might call into question the validity of one or both diagnoses. However, Links and Vignarajah do show some negative impact of the co-morbid state on treatment outcome. In some studies, patients with BPD and PTSD receiving psychotherapy for PTSD show less improvement and are more likely to drop out than patients without BPD (Feeny, Zoellner, \& Foa, 2002; Hembree, Cahill, \& Foa, 2004; McDonagh et al., 2005). For this reason, as 
well as concerns about suicidal behaviour, Links and Vignarajah recommended treatment of the BPD before targeting the PTSD diagnosis in the case presented in their report. In her treatment manual for dialectical behaviour therapy (DBT), Linehan (1993) recommends the use of exposure procedures in DBT to target PTSD symptoms that occur in patients with BPD. However, details of precisely how exposure would be incorporated into DBT were not included and exposure has not been explicitly incorporated in BPD treatment outcome research to date. In two recent series of case studies, though, Harned and Linehan (2008) and Wagner and colleagues (Wagner, Rizvi, \& Harned, 2007) demonstrate the use of prolonged exposure with DBT in the treatment of patients with BPD and PTSD with very promising results. Nonetheless, in the absence of empirically supported treatments for co-morbid BPD and PTSD, we are left, as Wagner et al. (2007) aptly state, with 'a reliance on theory, idiographic assessment, and empirically supported principles of change' to guide our clinical work with this under-researched population.

\section{References}

Axelrod, S. R., Morgan, C. A., 3rd, \& Southwick, S. M. (2005). Symptoms of posttraumatic stress disorder and borderline personality disorder in veterans of Operation Desert Storm. The American Journal of Psychiatry, 162/2, 270-275.

Bremner, J. D., Licinio, J., Darnell, A., Krystal, J. H., Owens, M. J., Southwick, S. M., Nemeroff, C. B., \& Charney, D. S. (1997). Elevated CSF corticotropin-releasing factor concentrations in posttraumatic stress disorder. The American Journal of Psychiatry, 154/5, 624-629.

Bremner, J. D., Randall, P., Scott, T. M., Bronen, R. A., Seibyl, J. P., Southwick, S. M., Delaney, R. C., McCarthy, G., Charney, D. S., \& Innis, R. B. (1995). MRI-based measurement of hippocampal volume in patients with combat-related posttraumatic stress disorder. The American Journal of Psychiatry, 152/7, 973-981.

Bremner, J. D., Staib, L. H., Kaloupek, D., Southwick, S. M., Soufer, R., \& Charney, D. S. (1999). Neural correlates of exposure to traumatic pictures and sound in Vietnam combat veterans with and without posttraumatic stress disorder: A positron emission tomography study. Biological Psychiatry, 45/7, 806-816.
Bremner, J. D., Vermetten, E., Vythilingam, M., Afzal, N., Schmahl, C., Elzinga, B., \& Charney, D. S. (2004). Neural correlates of the classic color and emotional stroop in women with abuse-related posttraumatic stress disorder. Biological Psychiatry, 55/6, 612-620.

Brewin, C. R., Andrews, B., \& Valentine, J. D. (2000). Metaanalysis of risk factors for posttraumatic stress disorder in trauma-exposed adults. Journal of Consulting and Clinical Psychology, 68/5, 748-766.

Carrasco, J. L., Diaz-Marsa, M., Pastrana, J. I., Molina, R., Brotons, L., Lopez-Ibor, M. I., \& Lopez-Ibor, J. J. (2007). Hypothalamic-pituitary-adrenal axis response in borderline personality disorder without post-traumatic features. The British Journal of Psychiatry, 190, 357-358.

Driessen, M., Herrmann, J., Stahl, K., Zwaan, M., Meier, S., Hill, A., Osterheider, M., \& Petersen, D. (2000). Magnetic resonance imaging volumes of the hippocampus and the amygdala in women with borderline personality disorder and early traumatization. Archives of General Psychiatry, 57/12, 1115-1122.

Feeny, N. C., Zoellner, L. A., \& Foa, E. B. (2002). Treatment outcome for chronic PTSD among female assault victims with borderline personality characteristics: A preliminary examination. Journal of Personality Disorders, 16/1, 30-40.

Gunderson, J. G., \& Sabo, A. N. (1993). The phenomenological and conceptual interface between borderline personality disorder and PTSD. The American Journal of Psychiatry, 150/1, 19-27.

Harned M. S., \& Linehan M. M. (2008). Integrating dialectical behavior therapy and prolonged exposure to treat cooccurring Borderline Personality Disorder and PTSD: Two case studies. Cognitive and Behavioral Practice, 15, 263-276.

Hembree, E. A., Cahill, S. P., \& Foa, E. B. (2004). Impact of personality disorders on treatment outcome for female assault survivors with chronic posttraumatic stress disorder. Journal of Personality Disorders, 18/1, 117-127.

Herpertz, S. C., Dietrich, T. M., Wenning, B., Krings, T., Erberich, S. G., Willmes, K., Thron, A., \& Sass, H. (2001). Evidence of abnormal amygdala functioning in borderline personality disorder: A functional MRI study. Biological Psychiatry, 50/4, 292-298.

Lange, W., Wulff, H., Berea, C., Beblo, T., Saavedra, A. S., Mensebach, C., Wingenfeld, K., \& Driessen, M. (2005). Dexamethasone suppression test in borderline personality disorder-effects of posttraumatic stress disorder. Psy choneuroendocrinology, 30/9, 919-923.

Liberzon, I., Taylor, S. F., Amdur, R., Jung, T. D., Chamberlain, K. R., Minoshima, S., Koeppe, R. A., \& Fig, L. M. (1999). Brain activation in PTSD in response to trauma-related stimuli. Biological Psychiatry, 45/7, 817-826.

Linehan, M. M. (1993). Cognitive-behavioral treatment of borderline personality disorder. New York, NY: Guilford Press. 
McDonagh, A., Friedman, M., McHugo, G., Ford, J., Sengupta, A., Mueser, K., Demment, C. C., Fournier, D., Schnurr, P. P., \& Descamps, M. (2005). Randomized trial of cognitive-behavioral therapy for chronic posttraumatic stress disorder in adult female survivors of childhood sexual abuse. Journal of Consulting and Clinical Psychology, 73/3, 515-524.

Minzenberg, M. J., Fan, J., New, A. S., Tang, C. Y., \& Siever, L. J. (2007). Fronto-limbic dysfunction in response to facial emotion in borderline personality disorder: An event-related fMRI study. Psychiatry Research, 155/3, 231-243.

Ozer, E. J., Best, S. R., Lipsey, T. L., \& Weiss, D. S. (2003). Predictors of posttraumatic stress disorder and symptoms in adults: A meta-analysis. Psychological Bulletin, 129/1, 52-73.

Perry, B. D., Giller, E. L., Jr., \& Southwick, S. M. (1987). Altered platelet alpha 2-adrenergic binding sites in posttraumatic stress disorder. The American Journal of Psychiatry, 144/11, 1511-1512.

Phan, K. L., Britton, J. C., Taylor, S. F., Fig, L. M., \& Liberzon, I. (2006). Corticolimbic blood flow during nontraumatic emotional processing in posttraumatic stress disorder. Archives of General Psychiatry, 63/2, 184-192.

Rinne, T., de Kloet, E. R., Wouters, L., Goekoop, J. G., de Rijk, R. H., \& van den Brink, W. (2002). Hyperresponsiveness of hypothalamic-pituitary-adrenal axis to combined dexamethasone/corticotropin-releasing hormone challenge in female borderline personality disorder subjects with a history of sustained childhood abuse. Biological Psychiatry, 52/11, 1102-1112.

Shin, L. M., Whalen, P. J., Pitman, R. K., Bush, G., Macklin, M. L., Lasko, N. B., Orr, S. P., McInerney, S. C., \& Rauch, S. L. (2001). An fMRI study of anterior cingulate function in posttraumatic stress disorder. Biological Psychiatry, 50/12, 932-942.

Silbersweig, D., Clarkin, J. F., Goldstein, M., Kernberg, O. F., Tuescher, O., Levy, K. N., Brendel, G., Pan, H., Beutel,
M., Pavony, M. T., Epstein, J., Lenzenweger, M. F., Thomas, K. M., Posner, M. I., \& Stern, E. (2007). Failure of frontolimbic inhibitory function in the context of negative emotion in borderline personality disorder. The American Journal of Psychiatry, 164/12, 1832-1841.

Southwick, S. M., Yehuda, R., Giller, E. L., Jr., \& Perry, B. D. (1990). Altered platelet alpha 2-adrenergic receptor binding sites in borderline personality disorder. The American Journal of Psychiatry, 147/8, 1014-1017.

Wagner, A. W., Rizvi, S. L., \& Harned, M. S. (2007). Applications of dialectical behavior therapy to the treatment of complex trauma-related problems: When one case formulation does not fit all. Journal of Traumatic Stress, 20/4, 391-400.

Yehuda, R., Southwick, S. M., Krystal, J. H., Bremner, D., Charney, D. S., \& Mason, J. W. (1993). Enhanced suppression of cortisol following dexamethasone administration in posttraumatic stress disorder. The American Journal of Psychiatry, 150/1, 83-86.

Zanarini, M. C., Frankenburg, F. R., Hennen, J., Reich, D. B., \& Silk, K. R. (2004). Axis I comorbidity in patients with borderline personality disorder: 6-year follow-up and prediction of time to remission. The American Journal of Psychiatry, 161/11, 2108-2114.

Zanarini, M. C., Frankenburg, F. R., Reich, D. B., Hennen, J., \& Silk, K. R. (2005). Adult experiences of abuse reported by borderline patients and Axis II comparison subjects over six years of prospective follow-up. The Journal of Nervous and Mental Disease, 193/6, 412-416.

Address correspondence to: Nicholas D. Giardino, PhD, Department of Psychiatry, University of Michigan, VA Ann Arbor Healthcare System, Mental Health Service, 2215 Fuller Road, Ann Arbor, MI 48105, USA. Email: ngiardin@umich. edu 